riais requerem; e d) a rapidez da evolução tecnológica, ou, em outras palavras, o cuidado que se deve ter com o fator conhecido como obsolescência planejada. Para esse último item Ronchi vai mais além e demonstra, através de gráficos e palavras, a evolução de um produto (fase de entrada, de expansão, de estabilização e de saturação, e, finalmente, o declínio de interesse).

A partir do terceiro capítulo a análise econômico-financeira tem presença marcante. Um exemplo disso é a afirmação de que a maior dificuldade que existe na determinação de objetivos econômicos de longo prazo deriva das metas empresariais que, em geral, são traduzidas em cruzeiros. A Ford Company - justifica o autor seu ponto de vista - teve como objetivos o incremento substancial dos lucros por ação e a consecução de uma determinada taxa de rentabilidade sobre as atividades empresariais. Isso foi em 1967. Considerando-se mais os planos de médio e longo prazos do que os de curta duração, o orçamento se torna, no livro, função básica na determinação da rentabilidade. É sugerido que um orçamento geral, que exponha de uma maneira globalizante, sem descer, portanto, a detalhamento setorial, representa uma constatação da validade dos programas que se pretende implementar. Entretanto, a fase preliminar, isto é, a fase na qual são determinados os objetivos, não pode deixar à margem considerações econômico-financeiras, já que segundo Ronchi, somente estas podem oferecer à empresa uma expressão sintética e significativa dos resultados que são previstos.

A empresa pode ter o lucro como resultado final desejado. Para isso a alternativa a ser escolhida deve ser aquela que dê maior rentabilidade global, lógica. É necessário examinar, neste caso, cada alternativa de ação que pode, na prática, ser representada em termos de gama de produtos, clientes, preços, volume de vendas e custos. Esses dados estão inter-relacionados e sua apresentação é complexa.

Finalmente, o controle de execução de planos a médio e longo prazos. A base para a utilização de controle é dada pelo sistema de feedback, que irá permitir um novo ciclo do processo. O con- trole é imprescindivel porque a existência de divergências - isto é, o gap existente entre o projetado e o que de fato ocorreu - é possivel e quase certa, mormente nos planos de longo prazo. Esse gap pode acontecer devido à imperfeição do plano, das distorções que se podem desenvolver quando da interpretação de objetivos e estratégias do plano e da intrínseca certeza da situação ambiental, que pode, como sugere a moderna teoria de sistemas abertos, influenciar e modificar o funcionamento da empresa.

Apesar do tema tratado - planejamento de longo prazo - e do conteúdo ser formado de conhecimentos específicos da área econômico-financeira, o livro pode ser de grande auxílio aos dirigentes que atuam dentro do campo administrativo.

Luís César G. de Araújo

\section{Curso Básico de Administração do Pessoal}

Por José Serson. $2^{a}$ ed. reescrita, São Paulo, Edições LTr, 1973. 495 p.

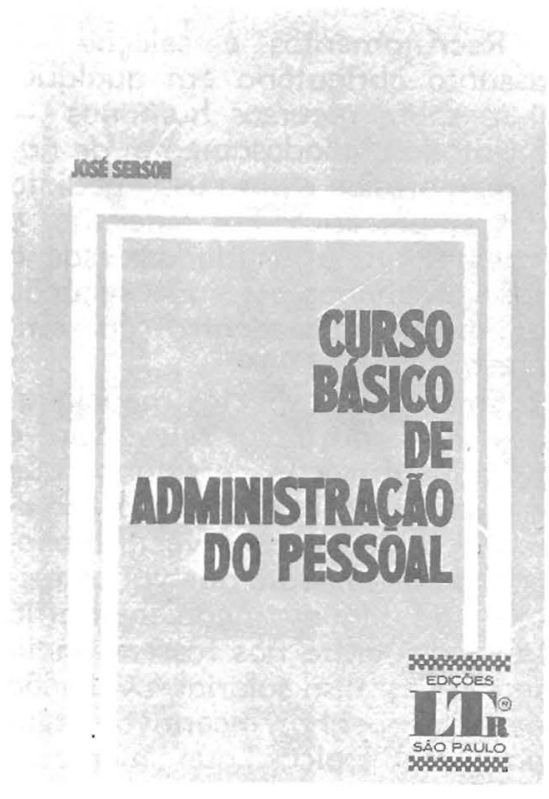

Para reescrever o Curso básico de administração do pessoal, o prof. José Serson serviu-se de extensos estudos bibliográficos e, também, de uma vivência de mais de 15 anos na orientação administrativa do pessoal de grandes grupos industriais em São Paulo.

O livro é escrito em linguagem clara e direta, operacional, e os assuntos são tratados sob aspecto empresarial, com preferência absoluta de aspectos de aplicação prática. Nota-se, contudo, que a visão teórica não foi abandonada. Ela serve de embasamento $e$ isso só fez com que o livro venha a se tornar praticamente obrigatório nas estantes de dirigentes, gerentes e estudantes da área administrativa.

Inicialmente, o livro dá uma interessante informação histórica do desenvolvimento da administração de pessoal no Brasil. Mostra Serson os objetivos pelos quais - complexo sistema de pessoal, que compõem as relações industriais, modernamente conhecidas como administração de recursos humanos, se desenvolveu ao longo do tempo.

Em seguida, o ensino de uma correta maneira de se realizar a descrição do trabalho a ser empreendido, mostrando com rique- 
za de detalhes todos os passos a serem percorridos pelo analista. Completando essa parte, o livro reforça a idéia de que se deve compreender o porquê da descrição do trabalho, principalmente, quando da implantação de um sistema de administração racional do pessoal.

Recrutamentos e seleção assunto obrigatório em qualquer livro sobre recursos humanos é tratado cuidadosamente, de natureza prática e para uso imediato dos empresários. Por extensão, o treinamento é estudado desde a fase preliminar até sua execução $e$ implantação dentro da empresa.

Embora os aspectos mencionados sejam da maior relevância, é na administração de salários que - livro alcança seu ponto máximo. A falta de uma vasta bibliografia não impediu que várias técnicas da administração salarial já utilizadas entre nós fossem analisadas. Pesquisa salarial, avaliação de desempenho, incentivos salariais são tópicos que merecem uma acurada observação, dado - grande potencial de aplicação que o assunto proporciona.

Depois de estudar o instrumental básico do desenvolvimento de recursos humanos - recrutamento, seleção, treinamento e salários - o livro se desdobra nos seguintes tópicos: estruturação de planos de beneficio, estrutura do plano de sugestões, estudos estatísticos da utilização de mão-de-obra, a função do psicólogo e do assistente social, organização e reorganização do setor de recursos humanos, e prevê a atuação da auditoria especificamente no campo objeto do livro.

Comparando o texto da primeira edição com o da segunda edição, encontramos os seguintes pontos de relevância:

1. Avaliação e classificação de cargos. Foi reformulado passando a abranger o estudo de novas experiências com os sistemas de comparação dois a dois e comparação por fatores, e que atualmente vem merecendo a atenção de especialistas das grandes empresas americanas, que os aplicaram e aperfeiçoaram a tal ponto que, de métodos antes condenados e rejeitados, passaram hoje a ser considerados como tão eficazes quanto os métodos tradicionais.
2. Treinamento e formação de recursos humanos. O autor passou a dar maior atenção à instrução programada em sua aplicação empresarial. A instrução programada tem sido considerada como a forma ideal de preparação de mão-de-obra, com extraordinária redução de custos e melhor aproveitamento por parte de alunos-empregados (estagiários). Esse sistema vem sendo utilizado em larga escala em empresas européias e não ganhou, entre nós, o destaque merecido.

3. Administração salarial. Foram incluidos esclarecimentos sobre o sistema interquartilar, com fórmulas de cálculos mais simplificadas do que as anteriores, o que torna mais rápido o cálculo e mais simples a formulação de conclusões das pesquisas salariais. A influência das novas medidas governamentais sobre aumentos sindicais, com a criação do salário normativo e dos aumentos proporcionais, foi analisada e também aplicada às faixas salariais obtidas pelos métodos tradicionais, que, por sua vez, são estudados um a um, com as minúcias de natureza prática.

4. Seleção de pessoal. Foi acrescido um bom número de informaçōes sobre o processamento da seleção de pessoal, divididas em cinco instrumentos de aferição das qualidades dos candidatos.

5. Recrutamento de pessoal. Foram equacionadas as diversas formas de recrutamento, de maneira a permitir ao recrutador segurança ao atuar sobre o mercado de trabalho. E de se ressaltar a maneira pela qual o autor adaptou os conceitos universais à realidade brasileira.

6. O psicólogo e o assistente social. A bibliografia sobre a atuação do psicólogo e do assistente social na administração de recursos humanos ainda não foi devidamente explorada. José Serson foi feliz, pois soube dar conteúdo do trabalho que é desenvolvido por esses profissionais na empreca brasileira.

Luis César G. de Araújo

\section{Sistemas Básicos de Controle de Estoques}

Por Robert Stansbury Stockton. São Paulo, Editora Atlas, 1972. Série Métodos Quantitativos, 139 p. Tradução do original Basic inventory systems, concepts and analysis, 1965, feita pelo prof. Dayr Américo dos Reis.

Após ter dado ao público brasileiro interessado lou de lingua portuguesa) uma série aprofundada de livros sobre compras, administração de materiais e almoxarifado, tais como Administração de materiais de Jorge Sequeira de Araújo, Compras de Stuart Heinritz e o Manual de administração de materiais de Sérgio Messias, a Editora Aitlas lançou o livro em epígrafe como um definitivo avanço em direção a uma maior quantificação dessa ciência de administração de materiais e estoques. De fato, os livros anteriormente existentes em língua portuguesa, como os citados e mais $\mathrm{O}$ método de compras, de England, não eram quantitativos e módernos no sentido da pesquisa operacional e da aplicação da estatística para previsões de estoques e probabilidade para - cálculo de atendimento. Neste pequeno volume, agora, existe um estudo satisfatório e claro que realmente preenche uma lacuna, pois o autor dessa resenha (e seus colegas) do Manual de administração da produção, da Fundação Getulio Vargas, escreveram capitulos de uma obra maior; acontecendo o mesmo com o livro de Maynard traduzido para o portugues. 